\title{
Percepção e conscientização ambiental sobre resíduos sólidos no ambiente escolar: respeitando os 5R's
}

\author{
Perception and environmental conscientization on solid waste in the \\ school environment: respecting the $5 R$ 's
}

Adriana Souza Santos', Nísia Maria París de Medeiros"

\section{RESUMO}

Essa pesquisa buscou identificar e analisar a percepção ambiental dos alunos da E. E. Prof. Paulo Pinheiro de Viveiros, situada na zona norte da cidade de Natal, sobre a problemática e conscientização ambiental de resíduos sólidos a partir da política dos $5 R^{\prime}$ s. Este trabalho foi realizado em três etapas distintas: levantamento dos conhecimentos prévios dos alunos (sondagem); aulas expositivas dialógicas (formação); elaboração pelos alunos de ações educativas de sensibilização ambiental. Os resultados demonstraram de forma geral que a percepção dos alunos em relação a essa temática é ingênua e restrita, com conceitos em sua maioria simplista e com base em seus conhecimentos prévios, e que essa percepção reflete em suas práticas ambientais. A formação proporcionou aos alunos conhecimentos para a elaboração de ações educativas de sensibilização ambiental. A elaboração de planos de ações pelos alunos com estratégias de sensibilização junto à comunidade escolar tem por objetivo despertar a consciência ambiental e estimular a participação dos envolvidos, além de propor oficinas e palestras para que educadores e alunos aprendam a reaproveitar e reciclar os resíduos utilizados. Os resultados revelam um caráter dinâmico atrelado aos conceitos ambientais, incentivando o exercício constante de novas formas de ver, sentir e agir sobre o mundo. Portanto, observa-se a importância de se inserir nas disciplinas curriculares a Educação Ambiental como um eixo transversal.

Palavras-chave: Educação ambiental; Política dos 5R's; Resíduos sólidos

\section{ABSTRACT}

This research sought to identify and analyze the environmental perception of the students of the E. E. Prof. Paulo Pinheiro de Viveiros, located in the northern part of the city of Natal, on the environmental problematic and awareness of solid waste from the 5R's policy. This work was carried out in three distinct stages: prior knowledge of the students (survey); dialogic expositive classes (training); elaboration of educational actions of environmental awareness by the students. The results showed in general that the students' perception regarding this subject is naive and restricted, with concepts that are mostly simplistic and based on their prior knowledge, and which this perception reflects in their environmental practices. The training provided the students with knowledge to elaborate educational actions of environmental awareness. The elaboration of action plans by the students with strategies of sensitization with the school community aims to awaken the environmental awareness and stimulate the participation of the involved ones, besides offering workshops and lectures for educators and students to learn to reuse and recycle the waste used. The results reveal a dynamic character linked to environmental concepts, encourages the constant exercise of new ways of seeing, feeling

'Mestre em Ensino de Ciências Naturais e Matemática (PPGECNM/UFRN). Atualmente, Professora de Biologia da Secretária de Educação do Estado do Rio Grande do Norte. E-mail: adss_santos@yahoo.com.br ORCID: https://orcid.org/0000-0002-1220-695X

"Graduada e Mestre em Geografia pela Universidade Federal do Rio Grande do Norte. 
and acting on the world. Therefore, it is observed the importance of inserting, in curricular subjects, Environmental Education as a transversal axis.

Keywords: Environmental education; 5R's policy; Solid waste

\section{INTRODUÇÃO}

Atualmente observa-se que o tema Educação Ambiental passou a ser recorrente no mundo inteiro, visto que o mesmo trata-se de uma alternativa na tentativa de educar e conscientizar o ser humano sobre questões relacionadas ao meio ambiente, principalmente acerca do uso adequado dos recursos naturais. Tornando-se dessa forma um tema relevante e de grande necessidade de ser incorporado ao processo educacional.

Percebe-se a necessidade da melhoria do mundo em que vivemos, pois de um modo geral regredimos em nossa qualidade de vida, visto que com o crescimento da população mundial, a cada dia aumenta também o número de poluidores, promovendo assim desequilíbrios ecológicos relacionados a condutas humanas inadequadas (CUBA, 2010).

Intensas modificações ocorreram na paisagem desde a Revolução Industrial, isso devido à capacidade de interferência do homem sob a natureza, o qual desenvolveu tecnologia a partir do uso de matéria prima, técnicas essas que viriam a facilitar a vida em sociedade, alavancando o consumismo exagerado. Com o processo de industrialização e a concentração da população nas cidades o lixo passou a ser um problema, sua coleta, tratamento e descarte passou a ser um assunto bastante conflitante. Segundo Romeiro (2001), esse progresso se configurou como grandes problemas ambientais, pois toneladas de dióxido de carbono $\left(\mathrm{CO}_{2}\right)$ foram lançadas na atmosfera, ocorreram degradações em diversos ecossistemas para extração de matéria prima, desmatamento acelerado, rompendo assim os ciclos da natureza, o que acabou contribuindo com o aumento acelerado da produção de resíduos sólidos.

Pensando sobre essa conjuntura, durante a década de 90 buscou-se refletir e organizar a prática pedagógica levando em consideração as questões ambientais, tendo como destaque a necessidade de trabalhar este tema nas escolas (FIGUEREDO, 2011). Neste período foi lançado pelo Ministério da Educação e Cultura, os Parâmetros Curriculares Nacionais (PCN's) o qual propôs a prática educacional dos temas transversais, tais como 
ética, pluralidade cultural, meio ambiente, saúde, orientação sexual, trabalho e consumo. Tais temas não constituem novas áreas ou disciplinas, estes devem ser trabalhados de forma contínua, sistemática, abrangente e integrados com as áreas pré-existentes nos PCN's. No documento referente ao meio ambiente destaca-se a necessidade de trabalhar a Educação Ambiental numa abordagem interdisciplinar e/ou transdisciplinar (BRASIL, 1998).

Para o sucesso da Educação Ambiental é necessário envolver a comunidade escolar nos problemas ambientais, desenvolver ações educativas de sensibilização ambiental, que tenham como objetivos esclarecer sobre questões ambientais e a relação interpessoal do homem em seu meio, despertando desta forma o interesse dos alunos e consequentemente sua percepção ambiental, tornando-os agentes participativos e atuantes quanto no desenvolvimento e planejamento de ações ambientais (NUNES, 2007).

A escola passa a ser um espaço privilegiado e de possibilidades para criar e estabelecer condições e alternativas que estimulem os alunos a terem concepções e posturas cidadãs, cientes de suas responsabilidades, desenvolvendo valores e atitudes comprometidas com a sustentabilidade ecológica e social (LIMA, 2004).

A Educação Ambiental vista desse ponto passa a ser uma ferramenta fundamental para o processo de gerenciamento de resíduos sólidos nos grandes centros urbanos, em que a separação destes deve ocorrer desde a sua fonte e de acordo com suas características, sendo assim, fundamental para a implantação das políticas de reciclagem e reutilização de materiais (ROCHA; SANTOS; NAVARRO, 2011). Essas atitudes devem ser propagadas e incentivadas entre os inúmeros atores sociais, com ênfase nas crianças e jovens, através das atividades escolares (ROCHA; SANTOS; NAVARRO, 2011).

Em relação à Educação Ambiental referente à gestão de resíduos sólidos, é importante que ela promova uma modificação nas atitudes, de maneira continuada, a partir de uma educação que proporcione o olhar crítico, reflexivo e contextualizado. Neste caso tomando-se como base a política dos 5R's, a qual se caracteriza pelos temas Reduzir, Repensar, Reutilizar, Reciclar e de Recusar consumir produtos que gerem impactos socioambientais significativos, pode-se abordar a questão dos resíduos sólidos com diferentes enfoques (FONSECA, 2000). Os 5R's fazem parte de um processo educativo, cuja abrangência a partir da não geração, tem por objetivo uma mudança de hábitos no cotidiano 
dos cidadãos, levando-os a repensar seus valores e práticas, reduzindo o consumo exagerado e o desperdício (BRASIL, 2018). De acordo com Fonseca e Campos (2012), esses temas podem ser observados não só no aspecto conceitual, mas como fatores favoráveis a geração de empregos, o aumento da competitividade empresarial, no avanço tecnológico, incentivador de procedimentos em defesa da ecologia, favorecendo o desenvolvimento sustentável.

Assim, pensar e agir de forma sustentável significa utilizar os recursos disponíveis hoje sem comprometer a vida das futuras gerações, promovendo consequentemente o equilíbrio entre fatores econômicos, financeiros, sociais e ambientais. Se tratando do ambiente escolar, a temática pode ser bastante estimuladora, em tratar os resíduos gerados em seu espaço de forma sustentável, ao conhecer sobre as leis referentes a resíduos sólidos, identificar de que forma a escola pode introduzir a temática em seu cotidiano, convertendo as informações adquiridas em conhecimento significativo aos alunos e para a comunidade escolar, e, sobretudo, promovendo mudanças e atitudes em relação ao consumo e aos resíduos gerados.

Portanto, o presente estudo tem como objetivo identificar e analisar a percepção ambiental dos alunos da Escola Estadual Professor Paulo Pinheiro de Viveiros, situada na zona norte da cidade de Natal, sobre a temática de resíduos sólidos e a conscientização ambiental em relação aos problemas ocasionados por esses resíduos a partir da política dos $5 R^{\prime} s$.

De acordo com Davidoff (1983, apud HANAl; NETTO, 2005), percepção é a capacidade que as pessoas apresentam de organizar e interpretar dados sensoriais para, a partir disso, desenvolverem a consciência do ambiente que as cercam. Nesse contexto, os problemas ambientais podem ser percebidos e interpretados de diferentes maneiras, visto que as pessoas encaram os problemas de acordo com as peculiaridades de suas percepções (SIRQUEIRA, 2008). A percepção ambiental é considerada uma precursora do processo que deperta a conscientização do individuo em relação às realidades ambientais observadas, visto que seu conceito é embasado nas diferentes formas que os seres humanos sentem, captam, percebem e se sensibilizam pelas ocorrências, manifestações dos fatos, fenômenos, realidades e mecanismos ambientais observados no meio em que vivem (MACEDO, 2000). 
Este estudo se trata do Trabalho de Conclusão de Curso da Pós-Graduação Lato Sensu de Educação Ambiental e Geografia do Semiárido, oferecido pelo Instituto Federal de Educação, Ciência e Tecnologia do Rio Grande do Norte, campus Educação à Distância. Esse projeto torna-se fundamental no ambiente escolar por contribuir para a sensibilização dos alunos quanto à preservação do meio ambiente a partir de ações educativas de sensiblização voltadas para resíduos sólidos gerados em seu ambiente.

\section{FUNDAMENTAÇÃO TEÓRICA}

\subsection{Resíduos sólidos}

O sistema sócio econômico vigente baseado no consumo, de um modelo capitalista, promove a produção de todo tipo de produtos, das mais diversas ordens e custo, em larga escala que levam tanto ao uso indiscriminado dos recursos naturais, quanto à produção exagerada de resíduos. A sociedade de consumo em que vivemos tem como hábito extrair da natureza a matéria prima e depois de utilizada, descartá-la de forma inadequada (FELIX, 2007).

No entanto, a biosfera apresenta um limite para prover recurso e absorver os resíduos, e cada vez mais os recursos são necessários, ao mesmo tempo em que mais resíduos são gerados, assim, grandes quantidades de produtos recicláveis, que poderiam ser reaproveitados, se tornam inúteis devido à má destinação final destes resíduos. De acordo com Azevedo (1996, apud FELIX, 2007), a destinação errônea desses produtos implica em perda ambiental, devido ao potencial poluidor e do mau gerenciamento dos resíduos gerados, comprometendo a qualidade do ar, do solo e das águas superficiais e subterrâneas.

Há uma preocupação em nível mundial em relação aos resíduos sólidos produzidos, em especial os gerados nos domicílios dos grandes centros urbanos, os quais necessitam de um adequado gerenciamento (JACOBI; BESEN, 2011). Desde a Conferência realizada no Rio de Janeiro em 1992 (ECO 92), o tema resíduo sólido vem sendo considerado prioridade em escala global, tanto para países ricos quanto para países em desenvolvimento. 
No Brasil o marco legal referente à limpeza urbana e a gestão dos resíduos sólidos são definidos na Política Nacional de Saneamento Básico, Lei n 11.445 de 2007(BRASIL, 2007), na qual o plano de resíduos sólidos deve integrar os planos municipais de saneamento. Em 2010, foi estabelecido um novo marco regulatório para o país com a Política Nacional de Resíduos Sólidos, Lei 12.305 (BRASIL, 2010) sendo regulamentada pelo decreto N 7.404 de 23 de dezembro de 2010. De acordo com o artigo $3^{\circ}$ da Lei 12.305/10, resíduo sólido é definido como:

Material, objeto ou bem descartado, resultante de atividades humanas em sociedade, cuja destinação se procede, se propõe proceder ou se está obrigado a proceder, nos estados sólidos ou semissólidos, bem como, gases contidos em recipientes e líquidos cujas particularidades tornem inviável o seu lançamento na rede pública de esgoto ou em corpos d’água, ou exijam para isso soluções técnicas ou economicamente inviáveis em face da melhor tecnologia disponível. (BRASIL, 2010, p.2).

Os resíduos sólidos podem ser classificados em orgânicos (úmidos), que compõe os restos de alimentos e resíduos sanitários, e em resíduos recicláveis (secos) que constituem em papel, plástico, vidro, dentre outros. Além desses, temos os resíduos tóxicos, considerados perigosos à saúde e ao meio ambiente, tais como: pilhas, baterias, medicamentos vencidos, tintas, solventes, lâmpadas e o lixo hospitalar.

\subsection{Processos de gestão dos resíduos sólidos}

A gestão dos resíduos sólidos gerados no meio urbano é marcada pela sua complexidade e diversidade de composição, o tratamento destes produtos significa prepará-los para algum tipo de reaproveitamento, redução de seu volume, redução de seu potencial de poluição ambiental e/ou de agressão à saúde humana (CANEDO, 2014). Sendo assim, os resíduos sólidos devem ser preparados ou dipostos de forma adequada para que possam ser tratados através de técnicas de reciclagem, compostagem e de incineração (MORAIS, 2005).

No Brasil a coleta seletiva é uma atividade que ainda não faz parte da rotina da maioria dos sistemas de limpeza pública municipais, sendo muitas vezes implantada e operada por programas específicos. Desta forma, a maioria dos resíduos sólidos 
recicláveis é destinada a lixões e aterros sanitários, bem como materiais tóxicos (baterias, medicamentos, tintas, lâmpadas) recolhidos em área urbana são descartados juntamente com os resíduos orgânicos, quando na realidade tais resíduos devem ser encaminhados para Pontos de Entrega Voluntária (PEV) ou Coleta Especial do município.

Em relação aos resíduos orgânicos, a compostagem é uma alternativa viável do ponto de vista ambiental, pois consiste em transformar a matéria orgânica em fertilizante utilizável na agricultura a partir de um processo biológico. Entretanto, para que a compostagem ocorra é necessário evitar a contaminação do composto com resíduos sólidos recicláveis a partir da coleta seletiva destes resíduos, para assim evitar a presença de quaisquer materiais que possam comprometer a qualidade da matéria orgânica (MORAIS, 2005).

\subsection{Educação Ambiental e a Política dos 5R's}

Para minimizar os impactos causados pelos resíduos sólidos é considerado importante que a população esteja sensibilizada para exigir atitudes ambientalmente corretas das empresas, e que estas aumentem a vida útil dos materiais vendidos ao consumidor (RIBEIRO, 2012). Para tanto, a Lei 12.305/10 (BRASIL, 2010) estabelece no Capítulo III, artigo $8^{\circ}$, parágrafo VIII que "a Educação Ambiental é uma das formas de almejarmos mudanças na postura das pessoas em relação ao consumo, as suas atitudes diárias, a partir de uma reflexão crítica sobre suas práticas diárias individual e coletivamente e mudá-las".

A Educação Ambiental é considerada uma práxis educativa social, que tem por finalidade a construção de valores, conceitos, habilidades e atitudes (LOUREIRO, 2011), e está relacionada com a prática das tomadas de decisões e a ética que conduzem para a melhoria da qualidade de vida (SATO, 2003). Um dos conceitos mais abrangentes para Educação Ambiental foi apresentado na Conferência Intergovernamental de Tbilisi (1977) e adotado internacionalmente, que diz: 
A Educação Ambiental é um processo de reconhecimento de valores e clarificações de conceitos, objetivando o desenvolvimento das habilidades e modificando as atitudes em relação ao meio, para entender e apreciar as inter-relações entre os seres humanos, suas culturas e seus meios biofísicos. (SATO, 2003, p. 23).

Para Reigota (2010) a Educação Ambiental é uma proposta que altera profundamente a educação, não devendo ser apenas uma prática pedagógica voltada para a transmissão de conteúdos referentes à ecologia e sim de promoção da participação dos cidadãos nas discussões e decisões sobre questões ambientais. Portanto, para Guimarães (2004) o objetivo da Educação Ambiental é de criticar, analisar os problemas ambientais a partir de uma visão socioambiental, política e econômica, tornando-se problematizadora, questionadora e integrada aos interesses das populações.

No ensino formal, a inserção da Educação Ambiental tem enfrentado inúmeros desafios, e o maior desafio é de inseri-lá nas práticas escolares de forma transversal (CARVALHO, 2005). Sato (2003) enfatiza que a Educação Ambiental tem sido reduzida a um tema a mais dentre os denominados temas transversais, deixando de explorar as intensas relações que existem entre os diversos eixos temáticos que formam o socioambiente em que vivemos.

Negre e colaboradores (2011) enfatizam que a Educação Ambiental é percebida como um processo permanente no qual os indivíduos e a comunidade tomam consciência do seu meio ambiente e constroem conhecimentos, valores, habilidades, experiências e determinação que os tornem aptos a agir individual e coletivamente para resolver problemas ambientais, presentes e futuros.

Nesse sentido, a Educação Ambiental é utilizada como instrumento de modificação cultural, inserindo no ambiente escolar os conceitos que evidenciam que o consumo seja realizado de forma consciente, mostrando impactos causados ao meio ambiente (FERNANDES; ROCHA, 2017). Atualmente sensibilizar quanto à geração e o descarte de resíduos sólidos considerando apenas os temas coleta seletiva e reciclagem é insuficiente, tornando-se interessante abordar a prática pedagógica dos 5R's que significam: Repensar, Recusar, Reduzir, Reutilizar e Reciclar. 
Os 5R's são norteadores para o desenvolvimento do tema resíduo sólido através da Educação Ambiental (BRASIL, 2018), partem do princípio de:

- Repensar - repensar os hábitos de consumo exige avaliar se o produto é realmente necessário. Após consumir o produto julgado necessário, deve-se saber descartá-lo, ou seja, praticar a coleta seletiva dos resíduos de forma correta e nas lixeiras adequadas para que possam ser reutilizados.

- Recusar - consiste em comprar produtos que não agridam ao meio ambiente. Ficar atento ao prazo de validade e adquirir produtos de empresas que tenham compromisso com a sustentabilidade ecológica.

- Reduzir - significa reduzir propriamente o consumo para evitar desperdício com gastos de água e energia.

- Reutilizar - caracteriza-se em ampliar a vida útil dos produtos, reutilizando-os quantas e quantas vezes puder ser aproveitado. Diminui-se assim, a extração da matéria prima para produção na indústria.

- Reciclar - consiste em aproveitar os produtos para a confecção de outros produtos, a técnica diminui a pressão sobre os resíduos sólidos e aumenta o emprego, seja de maneira formal ou informal.

Na Educação Ambiental, trabalhar abordando este formato é contribuir para que os cidadãos possam refletir sobre os modos de consumo, os tipos de produtos que adquirem (embalagens, durabilidade, dentre outros) e reflitam considerando que a reciclagem é apenas uma das alternativas (CANEDO, 2014).

\section{METODOLOGIA}

Pesquisa de cunho qualitativo, aplicada em três turmas do $9^{\circ}$ ano do Ensino Fundamental. Esta pesquisa apresenta três etapas distintas: levantamento dos conhecimentos prévios dos alunos (sondagem); aulas expositivas dialógicas referentes a resíduos sólidos e a política dos 5R's (formação); elaboração pelos alunos de ações educativas de sensibilização ambiental. 
Segundo Moreira (2000) os conhecimentos prévios são cognições já existentes na estrutura cognitiva do aprendiz, ou seja, são representações dos alunos que são levadas em consideração quando se pensa na aprendizagem significativa. Desta forma para identificar os conhecimentos prévios dos alunos foi aplicado um questionário semiestruturado. O questionário apresenta uma breve caracterização do aluno (série, turma, gênero, idade, e tempo que estuda na escola), porém sem identifcação do aluno, seguido de vinte questões referentes a concepções de Educação Ambiental, conceito, produção, coleta e descarte de resíduos sólidos, sendo que apresentava cinco questões abertas, em que os alunos deveriam responder conforme seus conhecimentos prévios e quinze questões fechadas, com opções a serem selecionadas, porém três destas questões necessitavam de complementação das respostas.

De acordo com Campos e Nigro (1999), a exploração dos conhecimentos prévios é importante tanto para os alunos quanto para o professor, pois ao conhecer as concepções dos alunos o professor poderá elaborar estratégias didáticas mais eficazes, já para o aluno pode servir para perceberem se mudaram ou não seus conhecimentos prévios, e assim avaliar sua aprendizagem.

Após a aplicação do questionário foi realizada uma intervenção na forma de aula expositiva dialógica, para esclarecer conceitos e direcionamentos quanto à geração de resíduos sólidos e os danos que estes causam ao meio ambiente, sendo divulgados os conceitos de lixo e resíduos sólidos, materiais recicláveis, coleta seletiva, tempo de decomposição, destino do lixo, poluição gerada, problemas acarretados pelo lixo para o homem e ao meio ambiente, e apresentado aos alunos à política dos 5R's. As aulas foram desenvolvidas com apresentações dos contéudos por meio de slides em datashow e de vídeos curtos selecionados no Youtube, que demonstraram os perigos do lixo descartado de forma incorreta, como realizar a coleta seletiva e a reciclagem, e como funciona a política dos $5 R^{\prime}$ s.

Como atividade avaliativa desta formação os alunos foram orientados a se aprofundarem no tema e elaborarem ações educativas de sensibilização ambiental referente à coleta e tratamento dos resíduos sólidos que pudessem ser aplicados no ambiente escolar. Cada turma ficou responsável por um determinado tipo de resíduo, 
os quais foram classificados em orgânico, recicláveis e tóxicos (perigoso). Para elaboração dos planos os alunos realizaram uma investigação junto à direção, coordenação e aos responsáveis da limpeza e cozinha sobre o descarte dos resíduos, e possíveis resíduos perigosos que a escola produz. Para a elaboração da ação foi solicitado uma pesquisa contendo os seguintes passos: caracterização do tipo de resíduo; o que o consumidor deve fazer (modo de separação, acondicionamento, coleta e transporte); o que o serviço público e fabricantes devem fazer (tratamento, disposição final, ações preventivas e/ou corretivas).

Em seguida, por turma, foram apresentados os possíveis planos de ações por tipo de resíduo, estes planos foram analisados e discutidos em sala, no intuito de definir uma única proposta especifica de ação para o seu tipo de resíduo. No plano de ação final deveria constar o objetivo da ação, o tipo de ação (enfatizando proceso de sensibilização), as ações efetivas e provável destino dos resíduos, além de explicarem como seria realizada a ação na escola.

Para o diagnóstico das respostas do questionário foi utilizada a técnica de análise de conteúdos de acordo com Bardin (2010). A análise de conteúdo constitui uma metodologia de pesquisa usada para descrever e interpretar o conteúdo de toda classe de documentos e textos, ajudando a reinterpretar as mensagens e a atingir uma compreensão de seus significados em um nível que vai além de uma leitura comum. Os dados qualitativos sofreram tratamento informático através de sistema estatístico em forma de porcentagem, além de serem apresentados em figuras e quadros, conforme necessidade.

\section{RESULTADOS E DISCUSSÕES}

\subsection{Caracterização da escola e Perfil dos alunos}

A Escola Estadual Professor Paulo Pinheiro de Viveiros, situada no Conjunto Nova Natal, bairro Lagoa Azul, área de periferia da zona norte da cidade de Natal/RN, foi inaugurada em 1984 como forma de acolher os alunos residentes do novo conjunto 
habitacional recém-inaugurado (1983). A escola apresenta em sua estrutura física sala da coordenação, secretaria, direção, sala dos professores, biblioteca, cozinha, refeitório, pátio, banheiros, 11 salas de aula ambiente, laboratório de ciências e de informática (ambos não funcionais), uma extensa área verde não utilizável e uma quadra poliesportiva em construção.

Atualmente a escola atua nos três turnos, no matutino com Ensino Fundamental anos finais do $6^{\circ}$ ao $8^{\circ}$ ano, no vespertino com Ensino Fundamental anos finais apenas com o $9^{\circ}$ ano, Ensino Médio e Promédio da $1^{a}$ série a $3^{a}$ série, e no turno noturno Ensino Médio Noturno Diferenciado da $1^{\mathrm{a}}$ a $3^{\mathrm{a}}$ série. A escola apresenta em seu quadro atual 40 professores e 824 alunos atuantes em seus três turnos de funcionamento. Além disso, a escola apresenta uma Companhia de Teatro denominada de Mythos, Escola de Xadrez, este ano foi implantado o projeto de robótica.

Nesta pesquisa foram analisados 79 (setenta e nove) questionários, aplicados a três turmas de $9^{\circ}$ anos do turno vespertino, deste total $52 \%$ são do gênero feminino e 43\% são do gênero masculino, $5 \%$ optaram por não responder esta questão; apresentam faixa etária entre 14 e 18 anos de idade, porém a faixa etária média é entre 15 e 16 anos, representando 29\% e 33\%, respectivamente. Em relação ao tempo que estudam na escola, identificou-se que 21,5\% estudam há 5 anos, 39,5\% há 4 anos, 15\% há 3 anos, 12,5\% há 2 anos e 18\% há 1 ano apenas na escola, 2,5\% não responderam esta questão.

\subsection{Conhecimentos prévios dos alunos}

Ao questionar aos alunos o que é lixo, observou-se que $24 \%$ não responderam à questão, das respostas obtidas foram identificadas quatro categorias: definição como algo não reutilizável (55,5\%), definição como algo que polui (10\%), definição como algo reciclável (4\%), definição incoerente (6,5\%) (Figura 1). Na categoria definição como algo não reutilizável foram agrupadas as respostas que identificam o lixo como algo sem serventia, sem utilidade, coisa usada, e o que não é reutilizado ou descartável. Na categoria definição como algo que polui foram agrupadas as respostas em que 
identificavam o lixo como um poluente do meio ambiente. Enquanto na categoria como algo reciclável os alunos enfatizaram como resposta a capacidade de reciclar o lixo. Já na categoria definição incoerente foram agrupadas as respostas fora de contexto da definição, tal como: o ser humano é um lixo, o lixo é uma droga.

Figura1 - Categorias e porcentagens identificadas como resposta na definição de lixo.

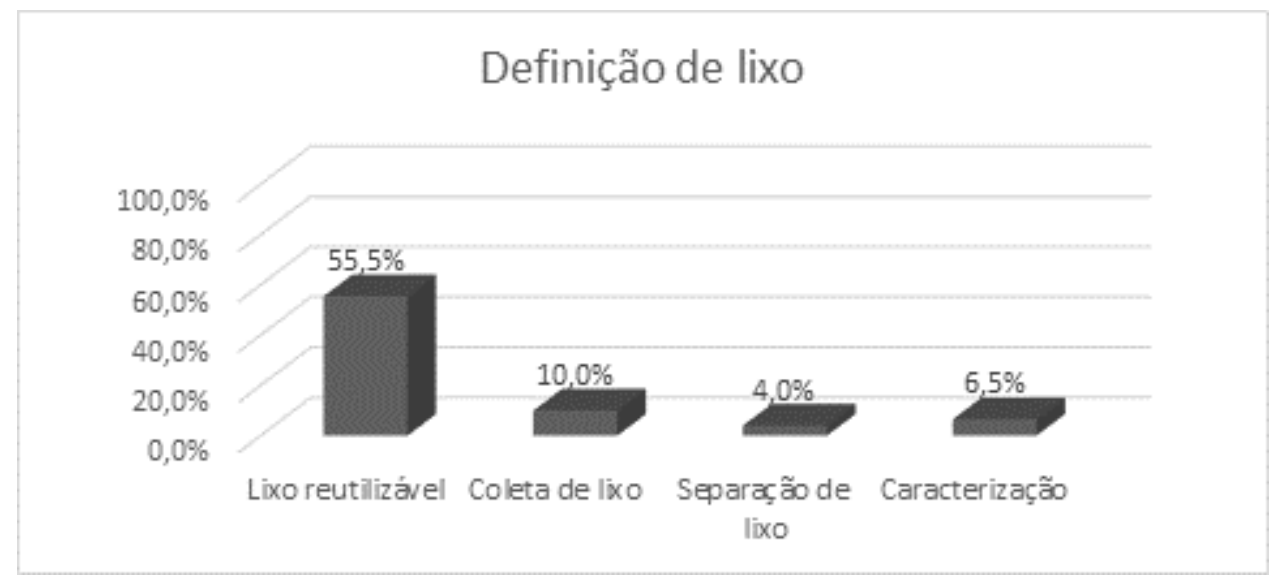

Fonte: Organização dos autores.

De acordo com Ferreira e Anjos (2001) o lixo é todo material que não pode ser reciclado ou reutilizado, sendo descartado e na maioria das vezes encontra-se em local inapropriado, ou seja, o lixo realmente passa a ser algo sem utilidade visto que são rejeitos dos Resíduos Sólidos os quais não podem ser reutilizados de forma alguma. Portanto, a categoria que apresentou maior representatividade, definição como algo não reutilizável, expressa de forma correta a definição de lixo.

Em seguida foi questionado aos alunos o que são resíduos sólidos, $60 \%$ dos alunos não responderam esta questão, das respostas obtidas foram identificadas três categorias: definição de lixo (10\%), definição por caracterização $(7,5 \%)$, e definição como algo resistente (22,5\%) (Figura 2). Na categoria definição de lixo os alunos informaram que resíduos sólidos e lixo são a mesma coisa; na categoria definição por caracterização os alunos citaram exemplos de resíduos sólidos; na categoria como algo resistente os alunos responderam que os resíduos sólidos são coisas que não se decompõem, algo duro que apresenta resistência (sólido), e até mesmo que não apresenta facilidade em desmanchar. 
Observa-se que para alguns alunos existe uma concepção distorcida do que são lixo e resíduos sólidos, uma vez que afirmam que esses termos são sinônimos, como visualizados na identificação da categoria definição de lixo. No entanto se sabe que lixo é todo material sem nenhuma possibilidade de reciclagem ou reutilização, e resíduo sólido é todo material sólido resultante das atividades diárias do homem em sociedade, o qual pode ser reutilizado ou reciclado. Em sua maioria os alunos não compreendem o conceito de resíduos sólidos, acreditando se tratar apenas de algo que esteja sólido, ou seja, em um dos estados físicos da matéria, sem explicitar a definição exata de seu significado.

Figura 2 - Categorias e porcentagens identificadas como resposta na definição de Resíduos Sólidos.

\section{Definição de Resíduos Sólidos}

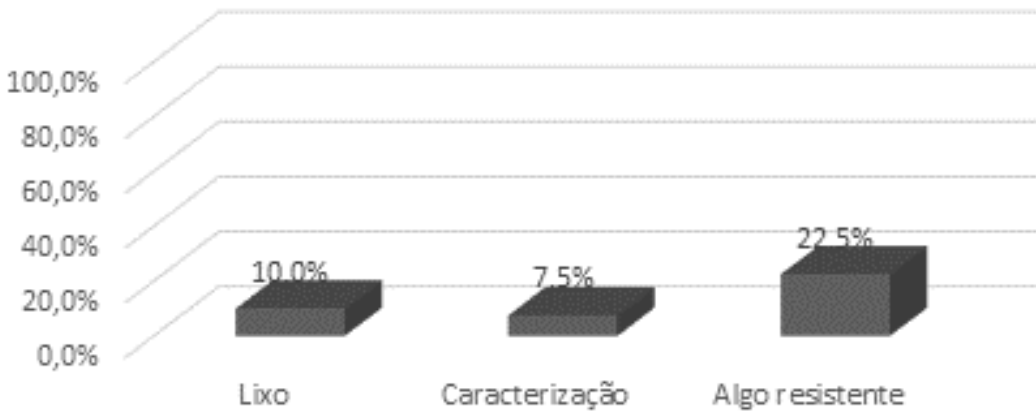

Fonte: Organização dos autores.

$\mathrm{Na}$ questão o que é coleta seletiva $54,5 \%$ dos questionários estavam sem resposta, das respostas obtidas emergiram cinco categorias: definição como ação de coleta (9\%); definição como recolhimento do lixo (11,5\%); definição como separação de resíduos (10\%); definição incoerente (5\%); e definição como algo reciclável (10\%) (Figura 3). Na definição como ação de coleta foram agrupadas as respostas em que os alunos comentaram que coleta seletiva é quando um grupo de pessoas coleta o lixo de algum ambiente. Na categoria definição como recolhimento de lixo foram agrupadas as respostas em que a coleta do lixo feita regularmente seria o mesmo que coleta seletiva. Na categoria definição como separação de resíduos, considerada a mais 
próxima da definição do tema, os alunos enfatizaram a separação dos resíduos como uma das etapas da reciclagem. Na categoria definição como algo reciclável os alunos responderam que coleta seletiva são objetos ou coisas recicláveis, sendo citados exemplos. Já na categoria definição incoerente foram agrupadas as respostas fora de contexto em relação ao tema.

Figura 3 - Categorias e porcentagens identificadas como resposta na definição de coleta seletiva.

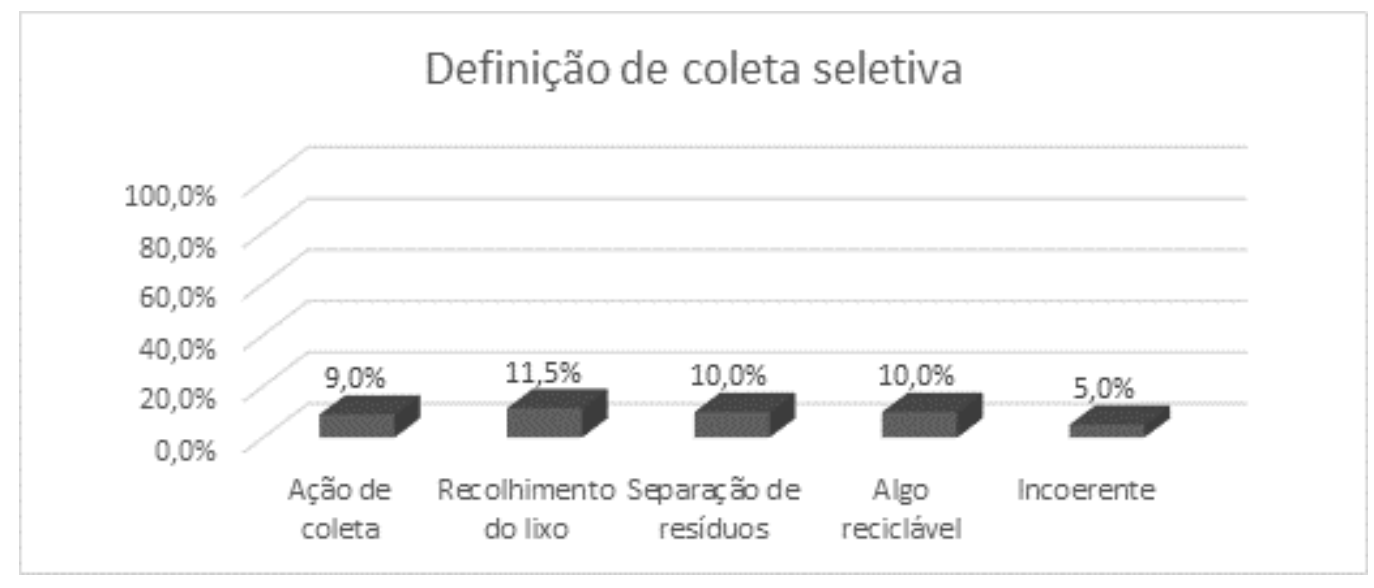

Fonte: Organização dos autores.

Nota-se ausência de informações a respeito do tema, visto que a coleta seletiva é o processo de recolher os resíduos como plásticos, papel, vidros, metais, dentre outros resíduos, que são devidamente separados pelas pessoas em suas casas, sendo estes destinados para os centros de reciclagem (GOUVEIA, 2003). Além disso, a coleta seletiva foi relacionada com o carro da coleta municipal que passa constantemente e com ações voluntárias desenvolvidas para recolhimento de resíduos sólidos em determinados ambientes.

Ao questionar sobre o que é reciclagem, 37\% não responderam à questão, em relação ás respostas dadas foram observadas quatro categorias: definição como lixo reutilizável (53\%); definição como coleta de lixo (2,5\%); definição como separação de lixo (2,5\%); definição por caracterização (5\%) (Figura 4). Na categoria definição como lixo reciclável foram agrupadas as respostas que informavam que reciclagem é o lixo que pode ser reutilizado, reaproveitado. Na categoria definição como coleta de lixo as 
respostas enfatizavam que a coleta frequente dos resíduos sólidos da cidade é reciclagem, enquanto que na categoria definição como separação do lixo se referia à coleta seletiva como reciclagem. Já a categoria definição por caracterização foi citada exemplos de materiais que podem ser reciclados.

Nenhum dos alunos apresentou o conceito de reciclagem de forma correta, pois de acordo com o CONAMA n. ${ }^{\circ} 307$ (BRASIL, 2002) reciclagem é o processo de reaproveitamento de um resíduo, após ter sido submetido à transformação. Todas as categorias identificadas nessa questão expressão outros conceitos, além de confirmar a inconsistência em relação a tratar lixo e resíduos sólidos como sinônimos, como visto em questionamentos anteriores.

Figura 4 - Categorias e porcentagens identificadas como resposta na definiç̧ão de reciclagem.

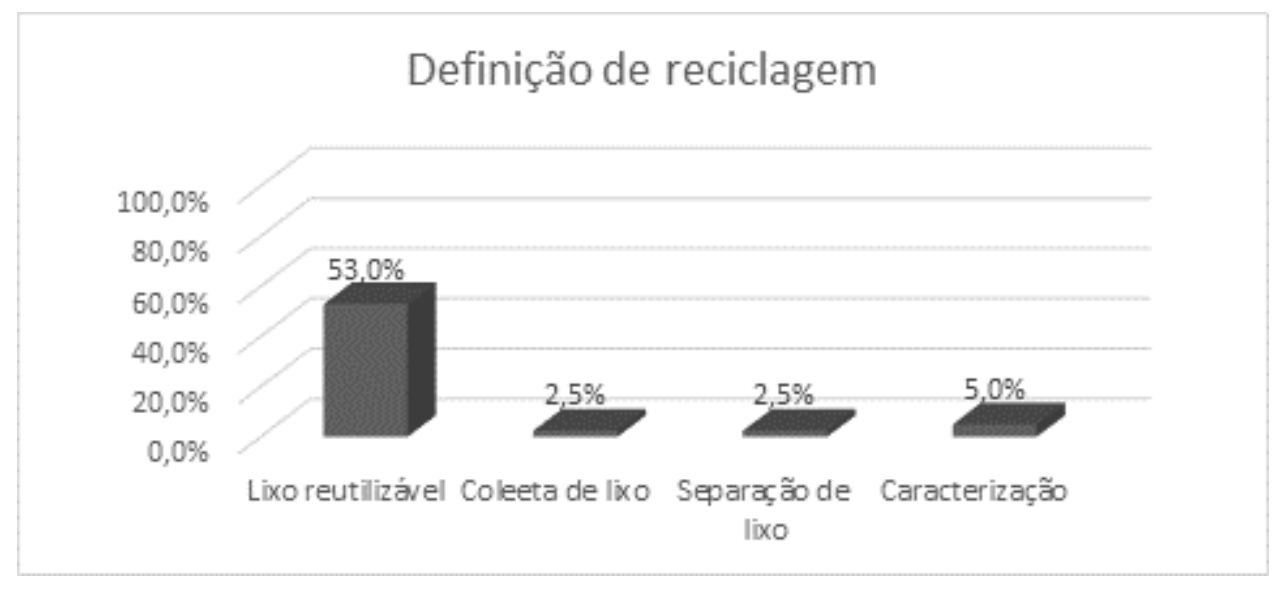

Fonte: Organização dos autores.

Quanto à importância da reciclagem para o meio ambiente e para o ser humano $42 \%$ dos questionários retornaram sem respostas, sendo identificadas cinco categorias de respostas: importância para diminuir a poluição (21\%); importância para preservação do meio ambiente (24\%); importância para a prevenção de doenças (6,5\%); importância econômica (5\%); e importância para manutenção da matéria prima (1,5\%) (Figura 5). Na categoria importância para diminuir a poluição foram agrupadas as respostas que relacionavam reciclagem a limpeza na cidade e no meio ambiente como em rios e praias. Na categoria importância para preservação do meio ambiente foram agrupadas 
as respostas que relacionavam a reciclagem a manutenção e conservação do meio ambiente, porém sem explicitar que manutenção e conservação seriam essas. Na categoria importância para prevenção de doenças foram agrupadas as respostas que relacionam a reciclagem com a prevenção e manutenção da saúde. Quanto à categoria importância econômica os alunos relacionaram ao dinheiro obtido com a venda dos materiais recicláveis em postos de coletas. Em relação à categoria manutenção da matéria prima citada apenas por um aluno o qual enfatizava que a reciclagem diminui o uso de matéria prima.

De acordo com as respostas dos alunos nesta questão observa-se que poucos alunos compreendem que existe uma relação entre os resíduos gerados pela ação humana e o meio ambiente, e que estes resíduos quando mal acondicionados e sem destinação adequada polui o meio ambiente trazendo diversos tipos de transtornos e impactos socioambientais, como poluição do ar, do solo e da água, bem como pode ocasionar danos à saúde.

Figura 5 - Categorias e porcentagens identificadas como resposta da importância da reciclagem.

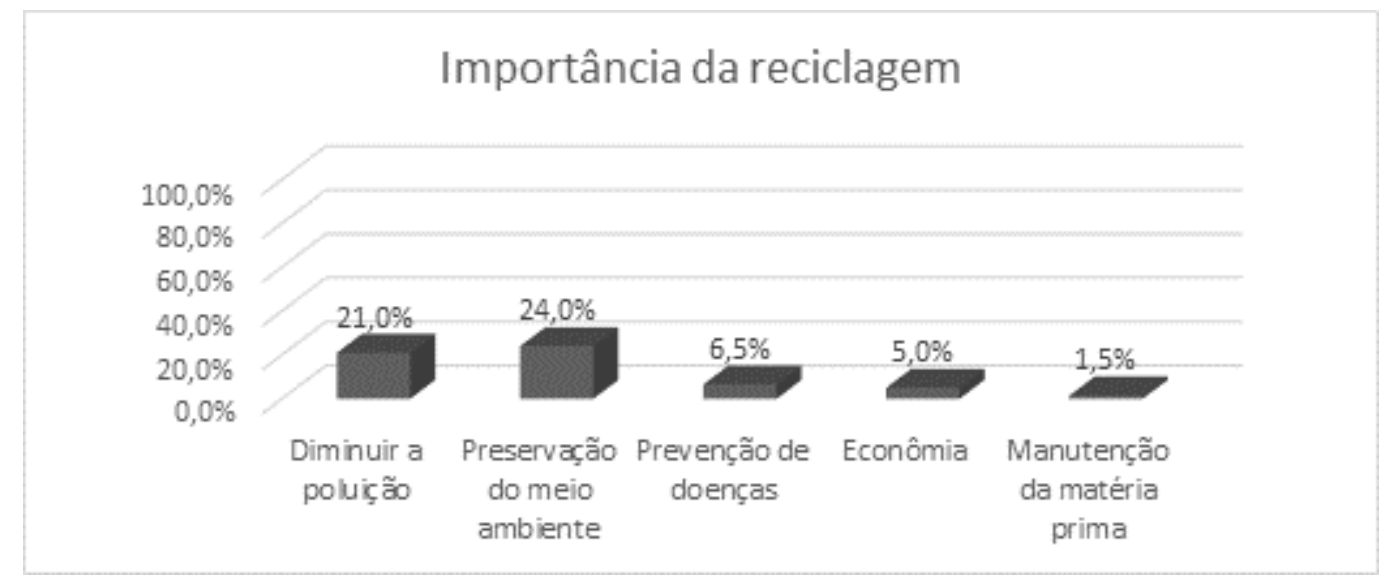

Fonte: Organização dos autores.

Em relação às respostas das questões fechadas, foi questionado aos alunos se costumam reutilizar algum tipo de objeto, 33\% responderam que sim, 30,5\% que não, $34 \%$ responderam que às vezes e $2,5 \%$ não responderam. Ao solicitar que 
complementassem a resposta informando de que objetos e de que forma eles reutilizam, observou-se que no caso de garrafas plásticas são reutilizadas para armazenar água, as sacolas plásticas são utilizadas como saco de lixo no dia a dia ou guardadas para armazenar outros produtos, potes e caixas são utilizados em decoração, sendo citada ainda a reutilização de papel de presente.

A questão seguinte perguntava se existe coleta regular do "lixo" em sua comunidade, obteve-se que $61 \%$ responderam que sim, $13 \%$ que não, $19 \%$ responderam que às vezes e $7 \%$ não responderam. Ao questionar de que forma é realizada a coleta em sua comunidade, $65 \%$ dos alunos enfatizaram que a coleta ocorre regularmente pela prefeitura, 10\% informaram que a coleta é feita por catadores, $20 \%$ disseram não saber como é realizada a coleta, e 5\% não responderam à questão. Em relação se sabem o destino dos resíduos coletados, 25,5\% responderam que são destinados para o aterro sanitário, 2,5\% enfatizaram o destino para algum terreno baldio, 30,5\% indicam que o destino é o lixão, 41,5\% não sabem para onde é enviado.

Tendo como base as respostas apresentadas, fica claro o desconhecimento por parte da maioria dos alunos da destinação final dos resíduos sólidos gerados. A prefeitura da cidade é responsável em coletar o lixo e resíduos sólidos da cidade, a coleta nos bairros é realizada três vezes por semana, conforme rota dos caminhões. Em Natal faz dez anos que o material coletado é tratado em um aterro sanitário na cidade circunvizinha Ceará-Mirim, situada a 34,5 km de distância da cidade de Natal. Porém no bairro existe uma grande área descampada (terreno baldio), próximo à escola, onde moradores lançam o lixo doméstico, e depositam alguns resíduos sólidos como poda de árvores, entulhos de reformas de casas e comércios, e até mesmo móveis e eletrodomésticos velhos. Portanto, acredita-se que a maioria dos alunos respondeu que os resíduos são transportados para um lixão, por acreditarem que o descarte é feito neste espaço próximo à escola. 
Quando questionado se em casa ocorre separação dos objetos recicláveis, observou-se que 10\% sempre separam, 7,5\% separam frequentemente, $43 \%$ separam de vez em quando, 39,5\% nunca separam. Em seguida foi perguntado se costumam limpar as embalagens separadas para reciclagem, quando elas estão sujas, sendo observado que 16,5\% sempre limpam, 7,5\% frequentemente limpam, 30,5\% limpam de vez em

Foi questionado se o óleo de cozinha utilizado é coletado para outros fins, 52\% informaram que sim e 48\% responderam que não realizam coleta do óleo de cozinha. A maioria dos alunos enfatizou realizar a coleta do óleo de cozinha pelo fato de que no ano anterior a escola fez uma coleta deste tipo de resíduo para realização de uma atividade escolar. Contudo acredita-se que a maioria dos alunos desconhecem os problemas causados por esse resíduo, portanto, consideramos que, mesmo a coleta sendo realizada, eles não apresentam conhecimentos a respeito do descarte correto

A pergunta seguinte questionava se eles tinham o hábito de jogar lixo na rua ou em locais públicos, $12,5 \%$ responderam que sim, 35,5\% responderam que não, 49,5\% responderam que às vezes, e 2,5\% não responderam. Em seguida foi questionado se saberiam separar corretamente, de acordo com os tipos de materiais fabricados, o lixo para reciclagem, 49,5\% respondeu que sim, 17,5\% responderam que não, $28 \%$ responderam que às vezes e 5\% não responderam. A questão posterior perguntava se os alunos se preocupavam com o descarte do lixo no meio ambiente, $70 \%$ disseram que sim, 10\% disseram que não, 20\% disseram que às vezes.

Foi questionado se os alunos conhecem a Política dos 5R's, 8,5\% responderam que sim e 91,5\% responderam que não. Como já enfatizado neste artigo a política dos 5R's consiste em incentivar a reutilização, a reciclagem, a redução, a recusa e o repensar sobre resíduos sólidos. É uma temática de conscientização que pelo visto ainda não foi apresentada a esta comunidade escolar. 
Em relação ao ambiente escolar foi questionado se os resíduos sólidos orgânicos são separados de outros resíduos sólidos, 8,5\% responderam que sim, 19\% responderam que não, 2,5\% responderam que às vezes e $70 \%$ responderam que não sabem se ocorre separação dos resíduos. Observa-se com essas respostas o quanto os alunos são alheios ao ambiente escolar, visto que na escola não existem coletores diferenciados para os resíduos orgânicos e sólidos recicláveis.

Quanto à existência de coleta dos resíduos recicláveis no bairro da escola, 21,5\% disseram que ocorre, $14 \%$ disseram que não ocorre, e $64,5 \%$ não sabem dizer se ocorre. Foi questionado ainda se na escola ou na comunidade existe ou já existiu ponto de entrega de resíduos sólidos perigosos, tais como baterias, pilhas, óleo de cozinha, entre outros: $25,5 \%$ responderam que não existe, $74,5 \%$ responderam que não sabem se existe. Essas respostas ressaltam a falta de conhecimento dos alunos em relação ao descarte dos resíduos sólidos de forma geral.

A segregação dos resíduos, separados de acordo com sua composição e matéria prima utilizada é uma etapa fundamental para a política de reciclagem e reutilização de materiais (RUSSO, 2003). Portanto, existe uma necessidade de depositar esses resíduos em locais apropriados, que possam promover a reutilização e a reciclagem do que for possível, na tentativa de diminuir o uso de recursos naturais.

Na última questão perguntava se os alunos já teriam participado de algum evento ou palestra referente a resíduos sólidos, 5\% responderam que sim, 95\% responderam que não. Ao questionar quais temas foram trabalhados nestas ações, surgiu como reposta a separação do lixo. Para um número muito baixo de alunos a temática coleta seletiva e reciclagem foram vistas em algum momento de suas vidas escolares, demonstrado a grande necessidade de sensibilizar estes alunos quanto à produção, descarte e reciclagem dos resíduos sólidos e orgânicos no ambiente escolar.

Os resultados demonstram de forma geral que a percepção dos alunos em relação a lixo, resíduos sólidos, coleta seletiva e reciclagem é ingênua e restrita, com 
conceitos em sua maioria simplista e com base em seus conhecimentos prévios, e que essa percepção reflete em suas práticas ambientais, visto que a maioria não separa e nem trata seus resíduos. Percebe-se ainda uma visão fragmentada em relação às questões ambientais e a geração dos resíduos, fica evidente que necessitam de uma conscientização ambiental referente aos problemas ambientais atuais que visem aumentar suas concepções sobre a temática dos resíduos sólidos.

\subsection{Intervenção e produção de ações educativas de sensibilização}

Como intervenção, foram realizadas quatro aulas expositivas dialógicas referentes a resíduos sólidos e a política dos 5R's, em cada turma, como explicitado na metodologia. Durante as aulas a cada conceito trabalhado foram apresentadas as categorias de respostas obtidas com o questionário de sondagem, como forma de desfazer qualquer concepção alternativa dos alunos. Obsevou-se ainda neste momento a participação efetiva da maioria dos alunos ao contarem suas experiências, histórias da comunidade, bem como ao citarem exemplos, e ainda enfatizaram suas dúvidas no momento em que estavam respondendo ao questionário de sondagem.

Em seguida, como forma avaliativa, foi solictado aos alunos a elaboração de planos de ações educativas referente ao descarte e reciclagem dos resíduos sólidos. Cada turma ficou responsável por um tipo de resíduo, o $9^{\circ} \mathrm{A}$ ficou responável pelos resíduos sólidos recicláveis, o $9^{\circ} \mathrm{B}$ pelos resíduos sólidos orgânicos, e o $9^{\circ} \mathrm{C}$ pelos resíduos sólidos perigosos. Todas as turmas foram orientadas a estruturarem grupos de trabalhos, a pesquisarem mais sobre o tema e identificar características do tipo de resíduo, como ocorre à separação, acondicionamento, coleta, transporte, bem como o tratamento, a disposição final e ações de prevenção ou correção quanto à poluição ocasionada por seu tipo de resíduo.

Nessa primeira fase de construção das ações em grupos, o $9^{\circ} \mathrm{A}$ elaborou três ações educativas referentes a resíduos sólidos recicláveis (Quadro 1). Em relação aos objetivos das 
ações, os alunos enfatizaram a diminuição da produção deste tipo de resíduo no ambiente escolar e a preservação do meio ambiente mediante a ação de reciclagem dos materiais.

Quadro 1 - Ações educativas, referentes à residúos sólidos recicláveis, elaboradas em grupos pelos alunos do $9^{\circ} \mathrm{A}$.

\begin{tabular}{|c|c|c|}
\hline GRUPOS & OBJETIVOS & AÇÕES \\
\hline Grupo 1 & $\begin{array}{c}\text { Incentivar os alunos a diminuírem a } \\
\text { produção de lixo na escola }\end{array}$ & $\begin{array}{c}\text { Realizar palestras; } \\
\text { Colocar coletores de recicláveis; } \\
\text { Colocar cartazes informativos; }\end{array}$ \\
\hline Grupo 2 & Preservar o meio ambiente & Realizar oficinas de reciclagem; \\
\hline Grupo 3 & $\begin{array}{c}\text { Diminuir o desperdício e a poluição } \\
\text { na escola }\end{array}$ & $\begin{array}{c}\text { Realizar palestras; } \\
\text { Colocar coletores de recicláveis; }\end{array}$ \\
\hline
\end{tabular}

Quanto às ações foram citados por dois grupos (grupo 1 e 3) a realização de palestras e a fixação de coletores para separação de materiais recicláveis, os quais não existem na escola, um dos grupos (grupo 1) ainda cita a fixação de cartazes informativos sobre coleta seletiva e reciclagem. Esses dois grupos se preocuparam em informar e sensibilizar quanto à importância da coleta seletiva dos resíduos, bem como no processo de separação desses materiais, porém não se preocuparam com o tratamento e disposição final dos resíduos, ou seja, o que será feito com os materiais coletados.

O grupo 2, por sua vez enfatiza como objetivo a preservação do meio ambiente, e elaborou uma ação voltada para o tratamento ou disposição final dos materiais coletados, porém não se preocupou em como seria a sensibilização na escola e como seria o sistema de coleta.

A turma do $9^{\circ} \mathrm{B}$, responsável pelos resíduos sólidos orgânicos, elaboraram três planos de ações educativas (Quadro 2). Nos objetivos foram enfatizados os verbos acabar com os resíduos orgânicos, conscientizar sobre resíduos orgânicos e informar como se devem descartar os resíduos orgânicos. Todos os grupos informaram como ação a construção de uma composteira no ambiente escolar, o grupo 2 agregou a essa ação a fixação de cartazes referente ao reaproveitamento da matéria orgânica. Os três grupos apresentaram ações com relação ao tratamento dos resíduos orgânicos, porém esqueceu-se de trabalhar o modo de separação, acondicionamento e coleta desse material, passo fundamental para que a compostagem possa dar certo. Além disso, 
também não enfatizaram a disposição final do produto da compostagem, e o que será feito com o fertilizante produzido nesse processo.

Quadro 2 - Ações educativas, referentes à residúos sólidos orgânicos, elaboradas em grupos pelos alunos do $9^{\circ} \mathrm{B}$.

\begin{tabular}{|c|c|c|}
\hline GRUPOS & OBJETIVOS & AÇÕES \\
\hline Grupo 1 & $\begin{array}{c}\text { Acabar com o lixo orgânico e ajudar } \\
\text { a natureza }\end{array}$ & $\begin{array}{c}\text { Fixar cartazes; } \\
\text { Construir uma composteira; }\end{array}$ \\
\hline Grupo 2 & $\begin{array}{c}\text { Conscientizar as pessoas sobre os } \\
\text { resíduos orgânicos }\end{array}$ & Construir uma composteira; \\
\hline Grupo 3 & $\begin{array}{c}\text { Informar como as pessoas devem } \\
\text { descartar seus resíduos orgânicos de } \\
\text { maneira sustentável }\end{array}$ & \\
\hline
\end{tabular}

Em relação aos resíduos sólidos perigosos, de responsabilidade da turma do $9{ }^{\circ} \mathrm{C}$, foi entregue apenas uma ação, a qual apresentava o objetivo de conscientizar os alunos quanto à preservação do meio ambiente e de controlar ao máximo o descarte dos resíduos sólidos perigosos. Em relação à ação foi citada a realização de palestras, de momentos de conscientização com coletas específicas de materiais perigosos ao meio ambiente, à elaboração de cartazes com informações referentes ao descarte destes materiais. Assim como as ações referentes a resíduos sólidos recicláveis essa turma não trabalhou o tratamento e a disposição final desses materiais como parte da ação educativa.

Após a análise dos planos de ações dos grupos pela professora mediadora, foi realizada a segunda fase de elaboração das ações, em que de cada turma deveria surgir apenas uma ação educativa construída com a participação de todos os alunos da turma. Nessa fase, em suas respectivas turmas, cada grupo apresentou de forma suscinta seus projetos de ações, após cada apresentação era dada a oportunidade dos outros grupos sanarem dúvidas quanto ao projeto apresentado.

Ao término das apresentações dos grupos foram enfatizados os pontos fracos e fortes de cada ação, principamente o que faltava em cada uma. A partir desse momento os alunos foram orientados a elaborarem um único projeto com base nos planos de ações apresentados em sala. Sendo definidos os objetivos, as atividades de 
sensibilização e conscientização, bem como atividades referentes ao tratamento e ao acondicionamento ou destino final dos resíduos. Além disso, foi solicitado aos alunos que informassem mais detalhes das ações a serem realizadas e que levassem em conta os conceitos verificados pelos grupos envolvidos para que as estratégias fossem construídas. As turmas tiveram 48 horas para elaboração dos planos de ações finais (Quadro 3), sendo entregue e apresentado por representantes dos grupos formados na primeira fase.

O plano de ação realizado pela turma do $9^{\circ} \mathrm{A}$, consta de: palestra educativa com ênfase em coleta seletiva e reciclagem; fixação de coletores para coleta seletiva; oficinas para produção de artesanato com materiais recicláveis, sendo sugerida a produção de peças que possam ser aproveitadas para o teatro da escola, e para eventos sociais promovidos pela mesma, como dia das mães; e repassar excedentes do material coletado pela escola para catadores locais ou artesãos.

No momento de discursão em sala sobre o plano de ação, os alunos lembraramse da iniciativa que um professor teve em anos anteriores de comprar um equipamento de fabricação de vassouras feitas com garrafas pets. Essa recordação deu ânimo aos alunos em ousarem na elaboração das oficinas de reciclagem e na doação do material coletado. Tendo agora um plano de ação que envolve conscientização, ação concreta e destinação aos resíduos.

Em relação aos resíduos sólidos orgânicos, a turma definiu em seu plano de ação: palestra educativa de conscientização e de separação e destinação dos resíduos orgânicos; montar uma composteira; montar uma horta escolar para utilizar o fertilizante produzido na compostagem; doar os excedentes do fertilizante para a comunidade escolar, e também doar o excedente de matéria orgânica para moradores que criam determinados tipo de animais.

Neste caso, foi observado pelos alunos que a escola atua nos três turnos, e que o sistema de compostagem montado poderia não ser suficiente para demanda da produção dos resíduos, sendo citada a ideia de doar o excedente para pessoas que criam determinados tipos de animais na localidade. A ideia surgiu de um aluno que 
trabalha meio período em um restaurante, o qual faz a doação desses resíduos para moradores alimentarem porcos e galinhas criados na localidade.

\section{Quadro 3 - Ações educativas finais elaboradas pelas turmas do $9^{\circ} \mathrm{A}, 9^{\circ} \mathrm{B}$ e $9^{\circ} \mathrm{C}$ em relação a resíduos sólidos recicláveis, orgânicos e perigosos, respectivamente.}

\begin{tabular}{|c|c|c|}
\hline TURMAS & OBJETIVOS & AÇÕES \\
\hline $9^{\circ} \mathrm{A}$ & $\begin{array}{l}\text { Promover a sensibilização } \\
\text { quanto à importância da } \\
\text { reciclagem dos resíduos } \\
\text { sólidos para o meio } \\
\quad \text { ambiente. }\end{array}$ & $\begin{array}{l}\text { Realizar palestras educativas sobre coleta seletiva e reciclagem; } \\
\text { Promover a coleta seletiva no ambiente escolar por meio de } \\
\text { coletores de material reciclável; } \\
\text { Realizar oficinas de recicláveis; } \\
\text { Repassar parte do material coletado para catadores locais ou } \\
\text { artesãos; }\end{array}$ \\
\hline $9^{\circ} \mathrm{B}$ & $\begin{array}{l}\text { Conscientizar a comunidade } \\
\text { escolar quanto à importância } \\
\text { da reciclagem dos resíduos } \\
\text { sólidos orgânicos; }\end{array}$ & $\begin{array}{c}\text { Palestras com a comunidade escolar sobre a separação, coleta } \\
\text { e importância da separação da matéria orgânica dos outros } \\
\text { resíduos; } \\
\text { Montar um sistema de compostagem do lixo orgânico } \\
\text { produzido pela escolar; } \\
\text { Elaborar uma horta escolar para reaproveitar o fertilizante } \\
\text { produzido na compostagem; } \\
\text { Repassar parte do fertilizante produzido para a comunidade } \\
\text { escolar; } \\
\text { Doar o excedente da matéria orgânica para alimentação de } \\
\text { animais criados no entorno da escola; }\end{array}$ \\
\hline $9^{\circ} \mathrm{C}$ & $\begin{array}{l}\text { Sensibilizar quanto ao perigo } \\
\text { de alguns produtos oferecem } \\
\text { quando não destinados de } \\
\text { forma correta }\end{array}$ & $\begin{array}{l}\text { Realizar palestra educativa referente à poluição ocasionada por } \\
\text { resíduos sólidos perigosos; } \\
\text { Montar postos de coletas de resíduos sólidos perigosos no } \\
\text { ambiente escolar; } \\
\text { Proporcionar destino correto a estes materiais - entregar em } \\
\text { ecopontos ou fabricantes; } \\
\text { Promover oficinas de reciclagem do óleo doméstico; }\end{array}$ \\
\hline
\end{tabular}

Quanto aos resíduos sólidos perigosos, o plano consta de: palestra educativa referente aos perigos e poluição ocasionada por esses resíduos, bem como de esclarecimentos referentes aos produtos considerados perigosos; montagem de posto de coleta de óleo, lâmpadas, baterias e pilhas; destinação deste material para os pontos específicos e adequados de coleta; produção de oficina de reciclagem do óleo de cozinha, ou seja, produção de sabão.

Mais uma vez no momento de discussão do plano de ação, os alunos remeteramse as suas lembraças de ações desenvolvidas pela escola, como a coleta do óleo de cozinha para a atividade da disciplina de artes, em que elaboraram sabão com o óleo de cozinha. Ainda comentaram sobre a ação da Companhia Energética do Rio Grande 
do Norte, COSERN, de trocar as lâmpadas fluorescentes por lâmpadas de led, quando na realidade eles poderiam doar as lâmpadas, mas realizaram também a coleta das lâmpadas antigas. Sendo fundamental para a elaboração deste plano, a observação

Observou-se, ao longo do processo de elaboração, uma melhora significativa dos planos de ações das turmas. Durante a primeira fase visualizou-se a dificuldade dos alunos em elaborarem seus planos, isso provavelmente se deva a falta de experiência dos alunos com esse tipo de atividade, ou seja, de estruturarem e escrever objetivos e metodologias de suas atividades/ações no ambiente escolar. Essa falta de experiência pode ser observada pela ausência de algumas etapas solicitadas de acordo com as orientações repassadas às turmas.

Porém, as elaboraçôes das ações enfatizam o processo de conscientização desses alunos, visto que refletiram sobre a separação e a coleta seletiva dos resíduos sólidos como forma de contribuir para a melhoria do meio ambiente, bem como buscaram promover o conhecimento dos efeitos nocivos à saúde devido ao descarte incorreto, resaltando assim a importância dessas ações. Além disso, observa-se a atitude social dos alunos quanto à destinação final do excesso dos resíduos sólidos coletados no ambiente escolar, em repassar os resíduos recicláveis para catadores locais, gerando renda para os mesmos, bem como a doação dos resíduos orgânicos para moradores que criam animais.

Pensando na política dos 5R's, não ficou clara a utilização desse sistema nos planos de ações, porém foi possível perceber características dos princípios de reciclar e reutilizar. Já os princípios de reduzir, recusar e repensar podem estar atrelados às palestras educativas propostas nos planos, contudo não constam nos planos os conceitos aplicados e a forma como serão apresentados.

Infelizmente os planos de ações dos alunos não serão aplicados ao longo deste ano letivo, visto que a escola passou por uma extensa reforma tendo paralisado as aulas por quase dois meses, atrasando desta forma o ano letivo em questão. Acreditamos que essas ações poderiam instigar a comunidade escolar, alunos, professores e demais funcionários, na reflexão sobre os produtos consumidos e descartados em seu cotidiano e sobre ações sustentáveis para descartar óleo de cozinha, pilhas, baterias e 
lâmpadas, de forma correta. Contudo, os alunos apresentaram a ideia deste tema para a gincana do ano letivo seguinte, e assim abranger toda a comunidade escolar com essa reflexão sobre as questões dos resíduos sólidos.

A proposta atuaria como norteador para escola com relação aos possíveis impactos que os resíduos sólidos possam provocar à saúde pública e ao meio ambiente, visando também o cumprimento de metas para redução dos resíduos gerados, parcerias com outras instituições públicas ou privadas para destinação ambientalmente correta dos resíduos, gerando emprego, reaproveitamento de materiais e reciclagem.

\section{CONSIDERAÇÕES FINAIS}

A análise dos dados ressalta que as percepções dos alunos confirmam a visão geral que a sociedade, em sua grande maioria, apresenta sobre resíduos sólidos, esta visão motiva a população a se livrar dos resíduos gerados de qualquer forma, não se importando com o destino final.

Para vencer as dificuldades e amenizar os impactos causados pelos resíduos sólidos, o indivíduo deve ter conhecimento básico (termos, leis) sobre a sua geração de resíduos, portanto, observou-se que é mais que necessário implantar a Educação Ambiental no âmbito escolar, não com ações pontuais responsabilizadas pelo profissional de Biologia ou Geografia, mais sim, de forma interdisciplinar atingindo todos os níveis de educação formal e informal.

A elaboração de planos de ações educativas pelos alunos com estratégias de sensibilização junto à comunidade escolar tem por objetivo despertar a consciência ambiental e estimular a participação dos envolvidos, além de propor oficinas e palestras para que educadores e alunos aprendam a reaproveitar e reciclar os resíduos utilizados. Mesmo apresentando dificuldades em elaborarem tais ações os alunos demonstraram interesse em contribuir para a disseminação do conhecimento adquirido ao longo deste processo.

Os resultados alcançados ressaltam a importância de se inserir, nas disciplinas curriculares, a Educação Ambiental como um eixo transversal. Na concretização deste 
projeto de ensino, as questões ambientais foram incorporadas ao Ensino de Ciências contribuindo para a formação de alunos/cidadãos, cada vez mais conscientes do seu papel de agentes de transformação social. Revelou, especialmente, um caráter dinâmico, posto que o conhecimento científico, em constante transformação, atrelado aos conceitos ambientais, incentiva o exercício constante de novas formas de ver, sentir e agir sobre o mundo.

\section{REFERÊNCIAS}

BARDIN, L. Análise de conteúdo. Lisboa, Portugal: Edições 70 LDA, 2010.

BRASIL. Ministério da Educação e Cultura. Secretaria de Educação Fundamental. Parâmetros Curriculares Nacionais: temas transversais. Brasília, 1998.

BRASIL. Resolução CONAMA n. ${ }^{\circ} 307$ - Estabelece Diretrizes, Critérios e Procedimentos para a Gestão dos Resíduos da Construção Civil. Brasília, 2002

BRASIL. Lei $n^{\circ}$ 11445, de 05 de janeiro de 2007. Estabelece Diretrizes Nacionais para o Saneamento Básico; altera as Leis nos 6.766, de 19 de dezembro de 1979, 8.036, de 11 de maio de 1990, 8.666, de 21 de junho de 1993, 8.987, de 13 de fevereiro de 1995; revoga a Lei no 6.528, de 11 de maio de 1978; e dá outras providências. Brasília, 2007.

BRASIL. Lei $n^{\circ} 12.305$ de 02 de agosto de 2010. Institui a Política Nacional de Resíduos Sólidos; altera a Lei n 9605, de 12 de fevereiro de 1998; e dá outras providências. Diário Oficial da União. Brasília, 2010.

BRASIL. Ministério do Meio Ambiente. A política dos 5R's, 2018. Disponível em: http://www.mma.gov.br/informma/item/9410-a-pol\%C3\%ADtica-dos-5-r-s. Acessado em: 01/07/2018.

CAMPOS, M.C.C.; NIGRO, R.G. Aquilo que os alunos já sabem. In: Didática de Ciências: o ensinoaprendizagem como investigação. São Paulo: FTD, p.78-97, 1999.

CANEDO, P. L. R. Resíduos sólidos urbanos como tema ambiental: reflexões a partir de um curso de educação ambiental semipresencial para professores do ensino básico. 2014. 124f. Dissertação (Mestrado em Ciências e Tecnologia Ambiental) Universidade Tecnológica Federal do Paraná, Curitiba, 2014.

CARVALHO, I. C. M. A invenção do sujeito ecológico: Identidade e subjetividade na formação dos educadores ambientais. In: SATO, M; CARVALHO, I.C. M. (orgs) Educação Ambiental: pesquisa e desafios. Porto Alegre, Artmed. 2005.

CUBA, M. A. Educação Ambiental nas escolas. Educação, Cultura e Comunicação - ECCOM, v. 1, n. 2, p. 23-31, jul./dez., 2010.

FELIX, R. A. Z. Coleta seletiva em ambiente escolar. Revista Eletrônica do Mestrado em Educação Ambiental, v.18, jan./jun., 2007. 
FERNANDES, P. R.; ROCHA, P. C. Coleta seletiva e escolas municipais: uma parceria possível através da Educação Ambiental. Estudo de caso: Escolas municipais da Estância Turística de Olímpia. In: $8^{\circ}$ Fórum Internacional de Resíduos Sólidos, Curitiba. Anais ... Curitiba, PR, junho, 2017.

FERREIRA, J. A.; ANJOS, L. A. Aspectos de saúde coletiva e ocupacional associados à gestão dos resíduos sólidos municipais. Caderno de Saúde Pública, Rio de Janeiro, n. 17, v. 3, mai./jun., 2001.

FIGUEIREDO, A. S. M. Os fazeres da Educação Ambiental nas escolas da Baixada Fluminense (RJ): um estudo sobre suas práticas e suas concepções. 2011. 119f. Dissertação (Mestrado em Ensino de Ciências). Instituto Federal de Educação e Ciência do Rio de Janeiro, Rio de Janeiro, 2011.

FONSECA, M. V. A. Rede 5R's: uma inovação de contexto no desenvolvimento de produtos e serviços a partir de rejeitos industriais no Brasil. In. Seminário Nacional sobre Reuso/Reciclagem de Resíduos Sólidos Industriais, São Paulo. Anais... São Paulo: Secretaria de Estado de Meio Ambiente de SP / Cetesp, 2000.

FONSECA, M. V. A.; CAMPOS, T. R. T. Rede 5Rs: a base estratégica para operacionalização da Política Nacional de Resíduos Sólidos, no âmbito industrial. In: XXXII Encontro Nacional de Engenharia de Produção, Bento Gonçalves. Anais... Bento Gonçalves, RS, outubro, 2012.

GOUVEIA, I. A. Diagnóstico dos resíduos sólidos no Shopping Center Iguatemi de Campina Grande-PB e uma proposta de implantação da coleta seletiva de tais resíduos. Universidade Estadual da Paraíba, João Pessoa, 2003.

GUIMARÃES, M. A Formação de educadores ambientais. Campinas, São Paulo: Papirus. 2004.

HANAI, F. Y.; NETTO, J. P. S. Percepção e conscientização ambientais: alternativas para a preservação das cavidades naturais do Parque Estadual Turístico do Alto Ribeira (Petar). Simpósio Nacional sobre Geografia, Percepção e Cognição do Meio Ambiente. Anais... Londrina, 2005.

JACOBI, P. R; BESEN, G. R. Gestão de resíduos sólidos em São Paulo: desafios da sustentabilidade. Estudos avançados, v.25, n.71, p. 135-158, 2011.

LIMA, W. Aprendizagem e classificação social: um desafio aos conceitos. Fórum Crítico da Educação: Revista do ISEP/Programa de Mestrado em Ciências Pedagógicas. v. 3, n. 1, out., 2004.

LOUREIRO, C. F. B. Educação Ambiental e movimentos sociais na construção da cidadania ecológica e planetária. In: LOUREIRO, C.F.B; LAYRARGUES, P.P.; CASTRO, R.S. (orgs). Educação Ambiental: repensando o espaço da cidadania. 5a Ed. São Paulo: Cortez, 2011.

MACEDO, R.L.G. Percepção e Conscientização Ambientais. Lavras: UFLA - Universidade Federal de Lavras/ FAEPE - Fundação de Apoio ao Ensino, Pesquisa e Extensão, 2000.

MORAIS, J.L. Estudo da potencialidade de Processos Oxidativos Avançados, isolados e integrados com tratamentos biológicos convencionais, para tratamento de chorume de aterro sanitário, 2015. 205f. Tese (Doutorado em Química). Universidade Federal do Paraná - UFPR, Curitiba, 2005.

MOREIRA, M. A Aprendizagem significativa subversiva. III Encontro Internacional sobre Aprendizagem Significativa. Anais... Lisboa, pp. 33-45, 2000.

NEGRE, T.S.; RABELO, M.V., SOUSA, G.E, SILVA, A.M, SILVA, G.A. Sensibilização ambiental: o caso do terraquarium em uma IES na cidade de Palmas/TO. Palmas, 2011. 
NUNES, E. R. M. A Formação da Consciência Ecológica Através da Educação Ambiental. Cartilha de Licenciamento Ambiental, Instituto Brasileiro do Meio Ambiente e dos Recursos Renováveis. 2 ed., Brasília, 2007.

REIGOTA, M. Meio ambiente e representação social. 8ª edição. São Paulo: Cortez, 2010.

RIBEIRO, F. Responsabilidade pós-consumo na política de resíduos sólidos: visão, estratégia e resultados até o momento no Estado de São Paulo. In: ABRELPE: Conexão Academia. 2012.

ROCHA, M. B.; SANTOS, N. P.; NAVARRO, S. S. Gestão de resíduos sólidos e educação ambiental: análise da percepção de estudantes do curso superior de Tecnologia em Gestão Ambiental. Revista Tecnologia \& Cultura, Rio de Janeiro, n 13, jul./dez., 2011.

ROMEIRO, A. R. Economia ou economia política da sustentabilidade? Texto para Discussão. IE/UNICAMP, Campinas, n. 102, set. 2001.

RUSSO, M. Tratamento de Resíduos Sólidos. Universidade de Coimbra. Faculdade de Ciência e Tecnologia. Coimbra, 2003.

SATO, M. Educação ambiental. ed. 1. São Paulo: Rima 2003.

SIQUEIRA, L. C. Política ambiental para quem? Ambiente social, Campinas, v. 11, n. 2, p. 425-437, 2008. 